\title{
Mental health status of health sector and community services employees during the COVID-19 pandemic
}

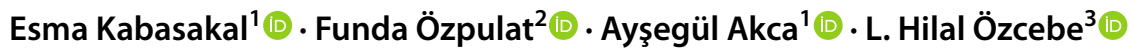

Received: 2 September 2020 / Accepted: 5 January 2021 / Published online: 9 March 2021

(c) The Author(s), under exclusive licence to Springer-Verlag GmbH Germany, part of Springer Nature 2021

\begin{abstract}
Purpose This study was conducted to evaluate the depression, anxiety and stress status of health sector and community service workers who were actively working during the pandemic period.

Methods This is a descriptive study. A total of 735 people consisting of 426 health sector employees and 309 service sector employees, constituted the study sample. In this study, the data were collected using the personal information form and the Depression Anxiety Stress Scales-21 (DASS-21). A regression model was established to test the effect of socio-demographic characteristics on depression, anxiety, and stress levels during the COVID-19 pandemic.

Results While there was no difference in working a second job across different sectors $(p=0.450)$, the household income $(p<0.001)$ and the increase in expenditures during the COVID-19 pandemic $(p<0.001)$ were different across the sectors. The scores of the overall scale and its sub-dimensions were significantly different across the sectors $(p<0.001)$. The DASS-21 scores were higher in the participants, who started to smoke more and who had their sleep duration decreased $(p<0.001)$. There is a statistically significant difference between social media use and the DASS-21 score $(p<0.001)$. There is a significant difference across all DASS-21 subgroups by the daily working hours in the health sector $(p<0.001)$.

Conclusion Our study provides significant findings regarding the mental health of individuals who continued working during the pandemic. To implement effective mental health interventions to risk groups and affected people in the COVID-19 pandemic, the recommendations of leading organizations, including WHO and ILO, should be implemented effectively concerning occupational health.
\end{abstract}

Keywords COVID-19 $\cdot$ Mental health $\cdot$ Occupational health $\cdot$ Health sector employee $\cdot$ Community services employee

\section{Introduction}

The World Health Organization (WHO) has described emergent pneumonia cases in Wuhan, China as a new coronavirus disease, namely COVID-19, that has not been detected in humans before (WHO 2020a). COVID-19 has rapidly spread from China to the whole world through human-to-human transmission and has turned into a global pandemic.

Ayşegül Akca

aysegulakca2014@gmail.com

1 Department of Nursing, Faculty of Health Sciences, Ankara Yıldırım Beyazıt University, Ankara, Turkey

2 Department of Nursing, Faculty of Health Sciences, Selçuk University, Konya, Turkey

3 Public Health, Faculty of Medicine, Hacettepe University, Ankara, Turkey
New arrangements such as unpaid leaves, part-time work, home office work, and online working have been implemented for employees in risk groups (pregnant women, individuals with chronic diseases, etc.) during the pandemic. However, various occupational groups including the employees of the health sector, logistics, food business, and cargo services continued their activities. As the number of people staying at home has increased during the COVID-19 pandemic, the significant increases have occurred in the volume of online shopping and mass purchasing of food and materials. Because of the stay at home measures introduced to the society, an increase occurred in delivery services, including cargo services or home delivery of bread and drinking water (KARID 2020). Employees in the health sector work under intense working conditions as a professional group that is most likely to encounter COVID-19 patients at the front stage during the pandemic. 
Besides, the increase in the workload during the pandemic, the highly contagious nature of COVID-19 and its transmission through various common means such as contact, breathing, and coughing have acted on the mental health of employees of the health and service sectors unfavourably by inducing fear, anxiety, and stress. It has been reported in the literature that people with COVID-19 (or suspected of having COVID-19) may experience intense emotional and behavioural reactions such as fear, boredom, loneliness, anxiety, insomnia or anger, as well as, manifesting severe reactions including committing suicide (Brooks et al. 2020). Although the rate of diagnosed COVID-19 patients with severe symptoms is relatively low compared to asymptomatic or mild cases, the psychiatric effects of the disease can lead to important consequences on the mental health of individuals (Wang et al. 2020). Therefore, addressing the mental state of employees during the pandemic is an important issue.

Although there are studies about the mental state of health sector employees in the literature (Chew et al. 2020; Zhu et al. 2020; Zhan et al. 2020), no studies are available about employees who work at different service sectors serving to meet the needs of people as unnamed heroes during the pandemic. The evaluation of the mental health of service sector employees who are actively working during the pandemic is important for developing psychosocial plans. In this respect, we think that this study will significantly contribute to the literature.

\section{Methods}

\section{Study design and participants}

This is a descriptive study. The study population consisted of health sector and service sector employees (workers in the logistics sector and cargo services; food industry employees including supermarket workers, cashiers, and booth attendants; greengrocers, butchers, bakers, drinking water dealers, catering sector workers, and non-governmental office workers); who continued their work actively during the COVID-19 pandemic. Sample selection was not performed in the study. Using the snowball sampling method, an online survey link was sent to individuals agreeing to participate in the study.

\section{Study inclusion criteria}

- Continuing work-life actively during the COVID-19 pandemic;

- Taking part in aid organizations such as the "Loyalty Support Group" and "Turkish Red Crescent"; and
- Being a non-governmental office worker with a likelihood of encountering individuals from the community.

\section{Study exclusion criteria}

- Not working actively during the COVID-19 pandemic;

- Flexible working schedules, working remotely from a home office, part-time working;

- Being an office clerk working in governmental institutions other than health institutions;

- Being on unpaid leave/vacation.

\section{Study sample}

A total of 762 people, including 441 health sector employees and 321 service sector employees, participated in the study. As a result of the evaluation of the study data, 27 individuals, who did not meet the inclusion criteria (currently not working in a job, being a civil servant, working remotely from a home office, being a student, etc.) were not included in the sample group. Consequently, a total of 735 people consisting of 426 health sector employees and 309 service sector employees, constituted the study sample. The health sector employees in the study sample were categorized according to the classification criteria used by WHO and ILO in studies on health sector employees. According to this classification, the participants from the health sector were from the following fields, including occupational and environmental health, infection control and prevention, management and human resources, mental health and psychosocial support, public health, and patient care (medicine, dentistry, dietetics, dentistry, etc.). The study included community health workers and health sector employees working at assisting and supporting positions, working in non-clinical jobs (cleaning, cooking, and food delivery and supply), and in administrative and office jobs.

Participants in the service sector were office and workplace employees (workers, engineers, technicians, repairmen, etc.), delivery-service employees (cargo workers, drinking water delivery workers, bread delivery workers, etc.), volunteers working in community services (the Loyalty Support Group and the Turkish Red Crescent Society), and employees serving the community at their workplaces (supermarket workers, greengrocers, butchers, grocers, bakers, cashiers, cleaners, booth attendants at supermarkets and bakeries, etc.).

\section{Study variables}

The independent variables in this study were:

- Sociodemographic characteristics;

- Working conditions; 
- Having relatives diagnosed with the disease; and

- Lifestyle.

The dependent variable of the study was the DASS-21 scores.

\section{Data collection tools}

Within the scope of this project the questionnaire included the questions on sociodemographic characteristics of the participants (personal information form), Depression Anxiety Stress Scales-21 (DASS-21), Fear of COVID-19 Scale (FCV-19S), Positive and Negative Mood Questions. In this article, findings regarding personal information form and Depression Anxiety Stress Scales-21 (DASS-21) questions are presented.

Personal information form: The sociodemographic characteristics form used in this study comprised 11 questions about age, gender, educational status, number of people living in the household, number of children younger than 18 years old in the household, previous experience in the current job, duration of experience in the present job, change in working schedules during the covid-19 pandemic, working a second job, household income and increases in expenditures. The lifestyle evaluation of the participants during the COVID-19 pandemic comprised 7 questions; which were the smoking status, physical activity, daily sleep time, social media use, alcohol consumption, number of meals per day, and appetite.

The Depression Anxiety Stress Scales-21 (DASS-21): Brown et al. developed DASS-21 in 1997 as a short form of the Depression Anxiety Stress Scales (DASS-42) developed by Lovibond and Lovibond in 1995 . The validity and reliability study of the scale in Turkish was conducted by Yilmaz et al. (2017). The score range of 0-9 points obtained from this scale indicates that depression is not a possibility, the range of $0-7$ points indicates the possibility of a normal level of anxiety, and the range of 0-14 points indicates the presence of a normal level of stress. In this study, the Cronbachalpha values of DASS-21 were calculated to be 0.964 for the overall scale; 0.926 for the depression dimension; 0.901 for the anxiety dimension; and 0.910 for the stress dimension of the scale. The Kaiser-Mayer-Olkin (KMO) value, which shows the construct validity and homogeneity of the scale, was found to be 0.970 . The Chi-squared value in Bartlett's test, which shows the statistical significance of factor correlations, was found to be $11,951.234\left(\chi^{2}=11,951.234\right.$; $p=0.000)$.

\section{Data collection}

The collection of the study data started on 15 May 2020 through an online survey. The data collection process ended on 01 June 2020 when the mandatory confinement restrictions to stay at home were lifted and the normalization process has been implemented in Turkey.

\section{Data analysis}

The study data were analysed using the SPSS 22.0 (Statistical Package for Social Sciences) software package. Number and percentage distributions were used as descriptive statistics. The Mann-Whitney U test, the Kruskal-Wallis test, and the chi-squared test were used for the analysis of nonparametric variables. A regression model was established to test the effect of socio-demographic characteristics on depression, anxiety, and stress levels during the COVID19 pandemic. The multiple regression analysis revealed the statistical significance of the model $\left(F=5.505, p^{<} 0.001\right)$. Socio-demographic characteristics (age, gender, occupation, previous experience in the current job, household income, daily working hours, changes in working hours, and increases in expenditures) were considered independent variables; whereas, the levels of depression, anxiety and stress were considered dependent variables.

\section{Reference categories}

The reference categories included the age of 45 years and older, male gender, working in the service sector; not having previous experience in the current job; income between 3.501 and 5.000 TRY; work hours in the range from 9 to $16 \mathrm{~h}$ a day; not having change in daily working hours during the COVID-19 pandemic; not having an increase in expenditures during the COVID-19 pandemic. The explanation power of the model was found to be $85 \%$.

\section{Ethical considerations}

Ethical approval to conduct the study was obtained from the Ankara Yıldırım Beyazıt University Ethics Committee (84892257-604.01.02-E.15646). The approval of the Ministry of Health was obtained via electronic submission. The information about the study was provided to the participants in the explanation section of the online survey. Participation in the study was voluntary.

\section{Results}

Of the participants from the service sector, $73.8 \%$ were males and $81.2 \%$ of the participants from the health sector were females $(p<0.001)$. The age distribution is different between the service sector and the health sector $(p<0.001)$. The level of education of the participants was different across the sectors. The high school graduates comprised 
$31.7 \%$ of the participants from the service sector and the individuals with an undergraduate degree comprised $50.2 \%$ of the participants from the health sector $(p<0.001)$ (Table 1).

The average length of employment was $9.23 \pm 2.46$ years in the service sector and $13.40 \pm 6.79$ years in the health sector. Almost half (46\%) of the employees in the service sector had previous experience in the same job. The length of previous experience in the current job was variable across the different types of sectors $(p=0.041)$. While there was no difference in working a second job across different sectors $(p=0.450)$, the household income $(p<0.001)$ and the increase in expenditures during the COVID-19 pandemic $(p=0.001)$ were different across the sectors (Table 1). An increase in expenditures was reported to occur in the kitchenfood expenses and the cleaning and hygiene expenses by $60.6 \%$ and $28.2 \%$ of the participants from the service sector, respectively.

The median DASS-21 score of the participants from the service sector was 6.00. The median scores of the overall scale and its sub-dimensions were higher in the health sector workers with a median DASS-21 score of 15.00 . The scores of the overall scale and its sub-dimensions were significantly different across the sectors $(p<0.001)$. Especially the health sector workers had higher median scores in the stress (normal 2, high 10) and depression (normal 2, high 11) sub-dimensions (Table 2).

There was a high likelihood of stress at rates of $4.4 \%$ $(n=13)$ and $6.3 \%(n=46)$ in the participants from the service sector and the health sector, respectively. The median stress score of the health sector workers was 18 . Anxiety scores were high in $13.3 \%(n=41)$ of those working in the service sector and $23.0 \%(n=98)$ of those working in the health sector. The median anxiety score of the health sector workers was 11 . High depression levels were found in $15.5 \%(n=48)$ of the participants working in the service sector and $30.0 \%(n=128)$ of the health sector workers. The median depression score of the health sector workers was 13 (Table 2).

The median score of DASS-21 was 21 among health sector employees, who reported that they worked 9-16 h per day. The hours worked a day was associated with the DASS-21 scores of health sector employees $(p<0.001)$. The median DASS-21 scores of the healthcare workers, who reported increased smoking and reduced daily sleep during the Covid-19 pandemic were 28 and 21, respectively. The DASS-21 scores were higher in the participants, who started to smoke more and who had their sleep duration decreased $(p<0.001)$. There is a statistically significant difference between the DASS-21 scores and both of these latter parameters. The median DASS-21 score of the health sector workers, who reported that they used social media less was 29 . There is a statistically significant difference between social media use and the DASS-21 score $(p<0.001)$. The median DASS-21 score was 13 in the service sector employees, who stated that the number of meals per day increased or decreased. The median DASS-21 score in the health sector employees was 24 , who reported a decrease in the number of meals a day. The DASS- 21 scores were lower in the service sector employees, who stated that the number of meals did not change. The DASS-21 scores were higher in the health sector employees, who reported that the number of meals a day decreased. There was a relationship between the number of meals a day and DASS-21 scores in the health sector employees $(p<0.001)$. Furthermore, there is a significant difference $(p<0.001)$ between appetite and DASS-21 scores in the employees of both sectors (Table 3).

There is a significant difference across all DASS-21 subgroups by the daily working hours in the health sector $(p<0.001)$. It is observed that participants, who worked fewer hours a day, had lower scores in all sub-dimensions. The health sector participants, who had increased expenditures during the COVID-19 pandemic, had higher anxiety sub-dimension scores $(p<0.001)$. The scores obtained from all sub-dimensions were higher in the health sector employees; who reported more smoking, shortened sleep duration, a decrease in the number of meals a day, and a decreased appetite during the COVID-19 pandemic $(p<0.001)$ (Table 4$)$.

In Table 5, the effects of socio-demographic and working characteristics on depression, anxiety and stress were examined and found to be statistically significant $(F=5.505$, $p<0.001)$. Working in the healthcare sector has a statistically significant and positive effect on depression, anxiety, and stress levels during the COVID-19 pandemic ( $\beta=0.169$, $t=3.576,<0.001)$. Similarly, working for $1-8 \mathrm{~h}$ has a statistically significant and negative effect on depression, anxiety, and stress levels $(\beta=-0.096, t=-2.380,<0.05)$. Also, a statistically significant and positive effect of having an increase in expenditures is observed on depression, anxiety, and stress levels $(\beta=0.115, t=3.200,<0.001)$. The explanation power of the model was found to be $85 \%$.

\section{Discussion}

The present study has evaluated the mental state of employees during the COVID-19 pandemic and highlights the important findings of employee health in terms of contributing to public health services.

The first finding of the study is that health sector employees experience more depression, anxiety, and stress compared to service sector employees during the pandemic (Table 2). Closer contact of health sector employees with COVID-19 patients increases the risk of contracting infection compared to employees from other sectors. Closer contact also increases the likelihood of transmitting the virus 
Table 1 Socio-demographic characteristics of the participants

\begin{tabular}{|c|c|c|c|c|c|c|c|}
\hline & \multicolumn{2}{|c|}{$\begin{array}{l}\text { Service } \\
\text { sector }\end{array}$} & \multicolumn{2}{|c|}{$\begin{array}{l}\text { Healthcare } \\
\text { sector }\end{array}$} & \multicolumn{2}{|c|}{ Total } & \multirow[t]{2}{*}{$P$} \\
\hline & $n$ & $\%$ & $N$ & $\%$ & $N$ & $\%$ & \\
\hline \multicolumn{8}{|l|}{ Age } \\
\hline $18-24$ & 97 & 31.4 & 171 & 40.1 & 268 & 36.5 & \multirow[t]{4}{*}{$<0.001$} \\
\hline $25-34$ & 121 & 39.2 & 181 & 42.5 & 302 & 41.1 & \\
\hline $35-44$ & 56 & 18.1 & 55 & 12.9 & 111 & 15.1 & \\
\hline 45 years and $\uparrow$ & 35 & 11.3 & 19 & 4.5 & 54 & 7.3 & \\
\hline \multicolumn{8}{|l|}{ Gender } \\
\hline Female & 81 & 26.2 & 346 & 81.2 & 427 & 58.1 & \multirow[t]{2}{*}{$<0.001 *$} \\
\hline Male & 228 & 73.8 & 80 & 18.8 & 308 & 41.9 & \\
\hline \multicolumn{8}{|l|}{ Educational status } \\
\hline Secondary school degree and $\downarrow$ & 56 & 18.1 & 3 & 0.7 & 59 & 8.0 & \multirow[t]{8}{*}{$<0.001$} \\
\hline High school graduate & 98 & 31.7 & 75 & 17.6 & 173 & 23.5 & \\
\hline Vocational school graduate & 41 & 13.3 & 50 & 11.7 & 91 & 12.4 & \\
\hline Undergraduate student & 39 & 12.6 & 24 & 5.6 & 63 & 8.6 & \\
\hline Undergraduate degree & 53 & 17.2 & 214 & 50.2 & 267 & 36.3 & \\
\hline Postgraduate education (continuing education) & 10 & 3.2 & 27 & 6.4 & 37 & 5.0 & \\
\hline Master's degree & 10 & 3.2 & 29 & 6.9 & 39 & 5.3 & \\
\hline Doctorate & 2 & 0.7 & 4 & 0.9 & 6 & 0.9 & \\
\hline \multicolumn{8}{|l|}{ Number of household members } \\
\hline $1-4$ & 193 & 62.5 & 339 & 79.6 & 532 & 72.4 & \multirow[t]{2}{*}{$<0.001 *$} \\
\hline 5 and $\uparrow$ & 116 & 37.5 & 87 & 20.4 & 203 & 27.6 & \\
\hline \multicolumn{8}{|l|}{ The number of children under the age of 18} \\
\hline $0-3$ & 300 & 97.1 & 417 & 97.9 & 717 & 97.6 & \multirow[t]{2}{*}{$0.405^{*}$} \\
\hline 4 and $\uparrow$ & 9 & 2.9 & 9 & 2.1 & & 2.4 & \\
\hline \multicolumn{8}{|l|}{ Previous experience in the current job } \\
\hline Yes & 142 & 46.0 & 161 & 37.8 & 303 & 41.2 & \multirow[t]{2}{*}{$0.041 *$} \\
\hline No & 167 & 54.0 & 265 & 62.2 & 432 & 58.8 & \\
\hline \multicolumn{8}{|l|}{ The length of previous experience in the current job } \\
\hline 1 year and $\downarrow$ & 68 & 22.0 & 155 & 36.4 & 223 & 30.3 & \multirow[t]{7}{*}{$<0.001$} \\
\hline $1-3$ years & 107 & 34.6 & 136 & 31.9 & 243 & 33.1 & \\
\hline $4-6$ years & 45 & 14.6 & 50 & 11.7 & 95 & 12.9 & \\
\hline $7-9$ years & 16 & 5.2 & 24 & 5.6 & 40 & 5.4 & \\
\hline $10-12$ years & 34 & 11.0 & 26 & 6.1 & 60 & 8.2 & \\
\hline $13-15$ years & 14 & 4.5 & 7 & 1.7 & 21 & 2.9 & \\
\hline 16 years and $\uparrow$ & 25 & 8.1 & 28 & 6.6 & 53 & 7.2 & \\
\hline \multicolumn{8}{|c|}{ Change in working hours compared to the period before the COVID-19 pandemic } \\
\hline Yes, the hours worked a day increased & 44 & 14.2 & 77 & 18.0 & 121 & 16.4 & \multirow[t]{3}{*}{0.133} \\
\hline Yes, the hours worked a day decreased & 144 & 46.6 & 169 & 39.7 & 313 & 42.6 & \\
\hline No, the hours worked a day did not change & 121 & 39.2 & 180 & 42.3 & 301 & 41.0 & \\
\hline Working a second job & & & & & & & \\
\hline Yes & 23 & 7.4 & 25 & 5.9 & 48 & 6.5 & $0.450^{*}$ \\
\hline No & 286 & 92.6 & 401 & 94.1 & 687 & 93.5 & \\
\hline Household income & & & & & & & \\
\hline 2000 TRY or $\downarrow$ & 31 & 10.0 & 4 & .9 & 35 & 4.8 & $<0.001$ \\
\hline $2.001-3.500$ & 124 & 40.1 & 65 & 15.3 & 192 & 26.1 & \\
\hline $3.501-5.000$ & 82 & 26.5 & 179 & 42.0 & 259 & 35.2 & \\
\hline $5.001-7.000$ & 44 & 14.2 & 85 & 20.0 & 128 & 17.4 & \\
\hline $7.000-10.000$ & 28 & 9.2 & 93 & 21.8 & 121 & 16.5 & \\
\hline Increase in expenditures in the COVID-19 pande & & & & & & & \\
\hline Yes & 184 & 59.5 & 253 & 59.4 & 437 & 59.5 & $<0.001^{*}$ \\
\hline
\end{tabular}


Table 1 (continued)

\begin{tabular}{|c|c|c|c|c|c|c|c|}
\hline & \multicolumn{2}{|c|}{$\begin{array}{l}\text { Service } \\
\text { sector }\end{array}$} & \multicolumn{2}{|c|}{$\begin{array}{l}\text { Healthcare } \\
\text { sector }\end{array}$} & \multicolumn{2}{|c|}{ Total } & \multirow[t]{2}{*}{$P$} \\
\hline & $n$ & $\%$ & $N$ & $\%$ & $N$ & $\%$ & \\
\hline No & 125 & 40.5 & 173 & 40.6 & 298 & 40.5 & \\
\hline Total & 309 & 100.0 & 426 & 100.0 & 735 & 100.0 & \\
\hline
\end{tabular}

*Fisher's exact test

to colleagues and family members (Temsah et al. 2020). According to data collected in April, 7428 health sector employees were diagnosed with COVID-19 in Turkey (T.R. Ministry of Health, 2020). Considering these findings together, it is likely that health sector employees will be psychologically affected more compared to employees from other sectors.

This study conducted in Turkey included nurses mostly. Despite the similarities of unfavourable mental health outcomes across health sector employees reported from other countries in the literature, this study shows that the health sector employees in Turkey are in better conditions compared to health sector employees in China. The health sector employees in China have been found out suffering from depression and anxiety at rates of $50.4 \%$ and $44.6 \%$, respectively. Of the health sector employees in Oman; it has been found out that $32.3 \%$ had depression, $34.1 \%$ had anxiety, and $23.8 \%$ had stress. A study conducted in Singapore and India found out that $10.6 \%$ of health sector employees suffered from depression, $15.7 \%$ suffered from anxiety, and 5.2\% suffered from stress (Badahdah et al. 2020; Chew et al. 2020; Lai et al. 2020). A review of the pandemics in the past reveals that health sector employees experienced psychological problems during the SARS and Ebola outbreaks, too (Lin et al. 2007; Wu et al. 2009; Ji et al. 2017). In this study, $72.1 \%$ of the participants from the health sector are nurses. Among health sector employees, especially nurses are reported to be suffering from depression, anxiety, insomnia, and stress (Lai et al. 2020). The nursing profession has a relatively difficult nature of work-life because it requires the provision of long-term and one-to-one care to patients.

The impacts of COVID-19 on both the public mental health and the mental health of employees are important indicators to be evaluated. A study on the Turkish population reported the scores of depression, anxiety, and stress in the participants as 6.26,3.34, and 5.99, respectively (Özdin et al. 2020). Comparing that study with the present one, we can argue that the DASS-21 scores of the service sector employees are similar to the scores obtained from the general population. Naturally, the levels of depression, anxiety, and stress will be high in people, who have to work outside the home (Mazza et al. 2020). However, the mental health of health sector employees was more adversely affected compared to the general population and service sector employees generally. This becomes an expected finding when the 12 times higher likelihood of contracting COVID-19 in health sector employees is compared to the general population (Nyugen et al. 2020).

The second finding of the present study is the strong correlation between the high and increased number of work hours with the experiences of depression, anxiety, and stress in health sector employees during the pandemic period (Sasangohar et al. 2020; Lai et al. 2020). During the COVID-19 pandemic, many health sector employees had to work more intensely, longer, or at irregular schedules than previously because of the increasing demand for health sector services (WHO 2020b). Immediate decisions were made and changes were implemented to the health system in Turkey as per the swift adaptation process to the pandemic. Such immediate changes included the increases in hospital bed capacity for COVID-19 patients, the assignment of health sector employees from different specialities to the care of COVID-19 patients, cancellation of all nonemergency leaves for 3 months, and the requirement to work for $24 \mathrm{~h}$ uninterruptedly. Long working hours, shifts, high workload, and other psychosocial hazards can cause fatigue, occupational burnout, and increased psychological distress or adverse effects on mental health (WHO 2020b; Sasangohar et al. 2020). While it has been reported that the personnel working in the intensive care unit in the fight against the epidemic are emotionally worn out (Sasangohar et al. 2020; Ruiz-Fernández et al. 2020), Teng et al. (2020) reported that depression (50.0\%), anxiety (23.4\%), and fatigue (73.7\%) are common among frontline workers. Working hours need to be rescheduled to alleviate the pandemic-related psychiatric symptoms in health sector employees who work under intense and demanding conditions. The increase in the daily working hours in $14 \%$ of the service sector employees did not induce a similar outcome. Differences in working conditions, work intensity, workload, and disease risk across types of professions are thought to cause different psychological outcomes. For employees outside the health sector, having a job during the pandemic, as well as having a lower risk of contracting the disease, may have favourably affected their psychology and prevented stress.

The third finding of our study is the significant relationship between socio-demographic characteristics (age, gender, educational status) and DASS-21 symptoms in health 


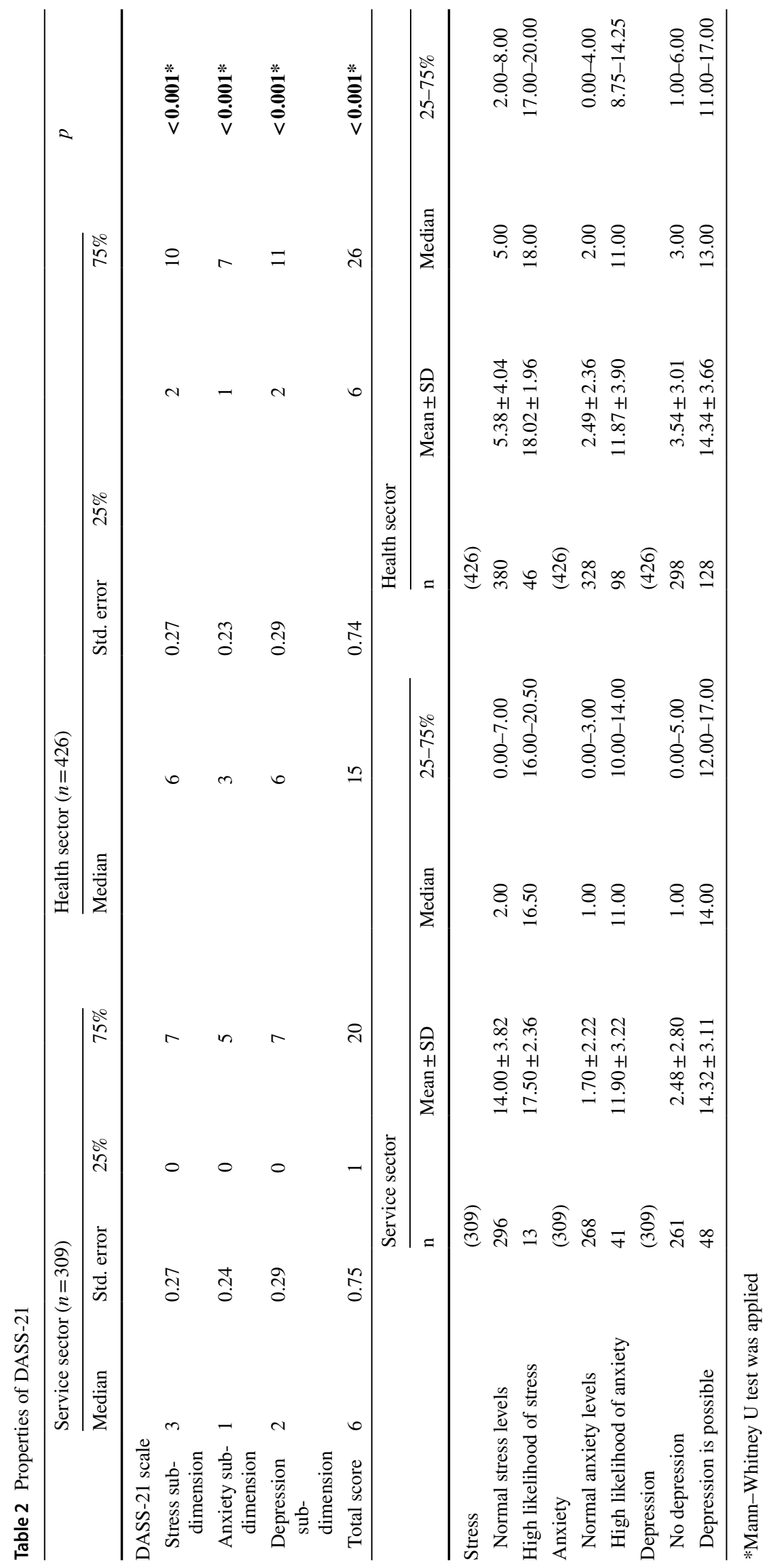




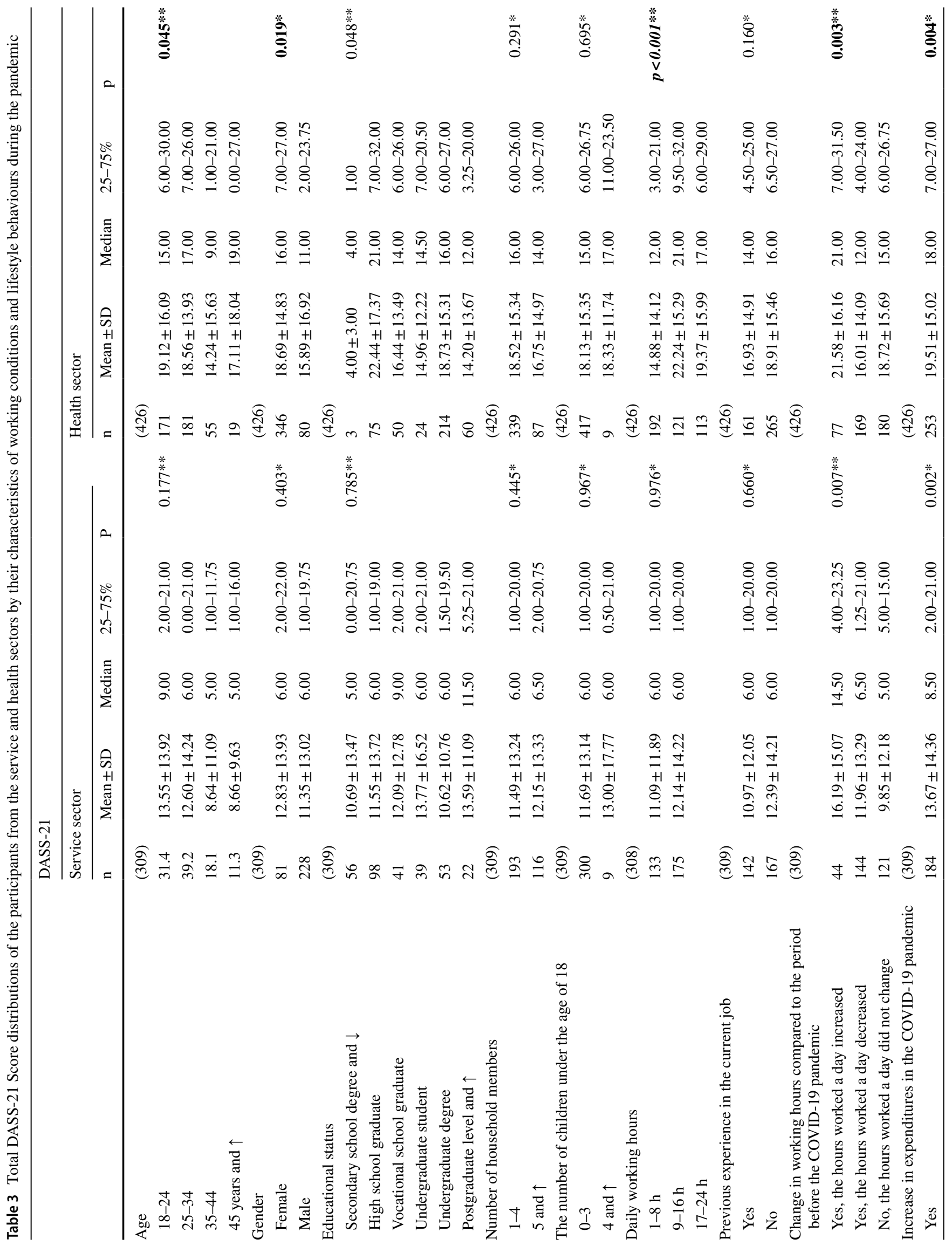




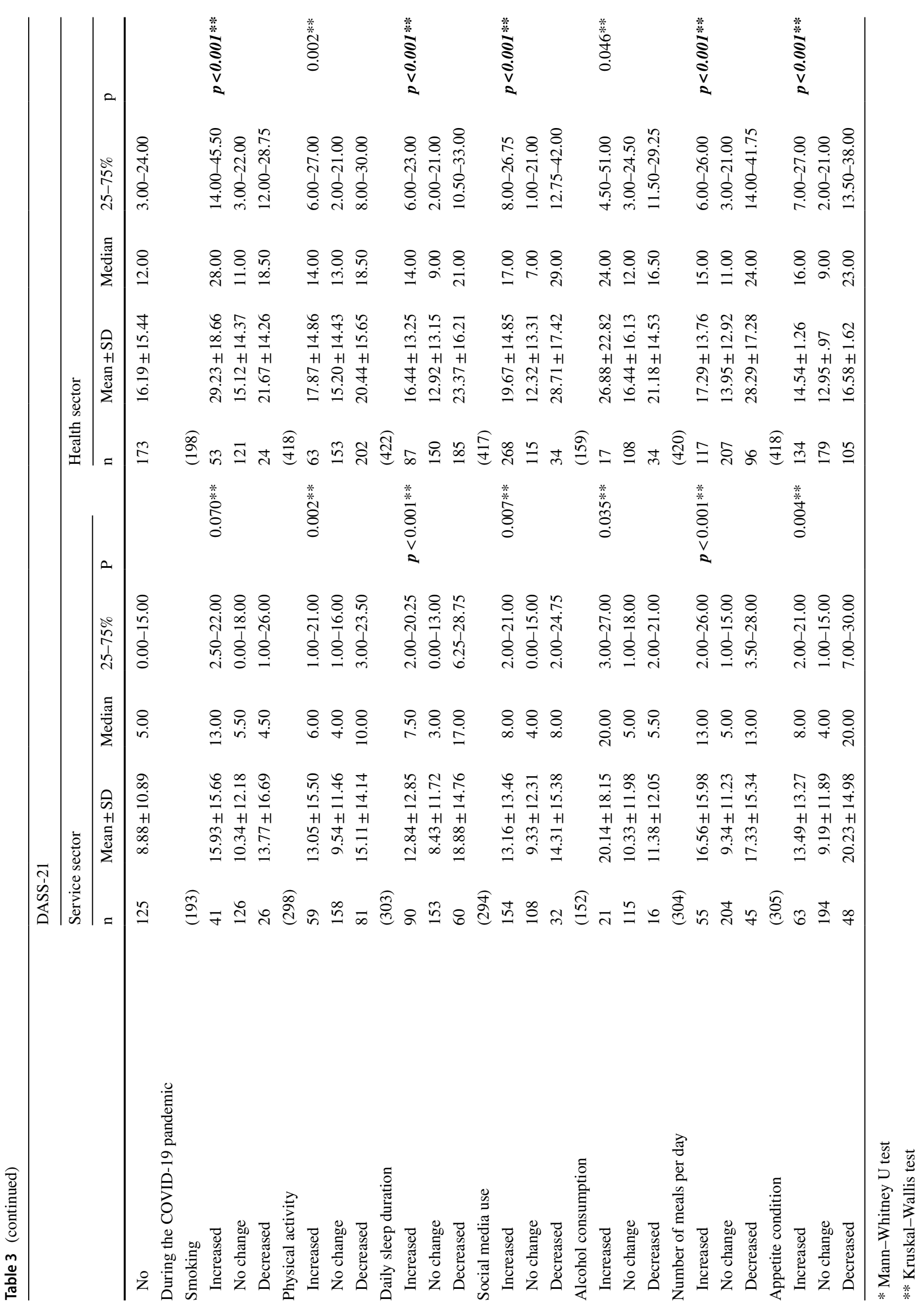


Table 4 Comparison of the analysis results of subgroups of DASS-21 by working characteristics and lifestyles of people from the service and health sectors during the pandemic

\begin{tabular}{|c|c|c|c|c|c|c|c|c|}
\hline & \multicolumn{4}{|c|}{ Service sector } & \multicolumn{4}{|c|}{ Health sector } \\
\hline & $\mathrm{n}$ & Stress & Anxiety & Depression & $\mathrm{n}$ & Stress & Anxiety & Depression \\
\hline Age & 309 & $0.566 * *$ & $0.229 * *$ & $0.022 * *$ & 426 & $0.045^{* *}$ & $0.589 * *$ & $0.020 * *$ \\
\hline Gender & 309 & $0.308^{*}$ & $0.693^{*}$ & $0.534^{*}$ & 426 & $0.041 *$ & $0.028^{*}$ & $0.032 *$ \\
\hline Educational status & 309 & $0.676 * *$ & $0.618 * *$ & $0.725 * *$ & 426 & $0.058 * *$ & $0.211 * *$ & $\mathbf{0 . 0 3 3} * *$ \\
\hline Number of household members & 309 & $0.668 *$ & $0.714 *$ & $0.363^{*}$ & 426 & $0.239 *$ & $0.970 *$ & $0.129 *$ \\
\hline The number of children under the age of 18 & 309 & $0.895^{*}$ & $0.755^{*}$ & $0.971 *$ & 426 & $0.474 *$ & $0.446^{*}$ & $0.349 *$ \\
\hline Daily working hours & 308 & $0.666^{*}$ & $0.807 *$ & $0.524 *$ & 313 & $p<0.001 * *$ & $p<0.001 * *$ & $p<0.001 * *$ \\
\hline Previous experience in the current job & 309 & $0.881^{*}$ & $0.825^{*}$ & $0.601^{*}$ & 426 & $0.150 *$ & $0.198 *$ & $0.221 *$ \\
\hline $\begin{array}{l}\text { Change in the hours worked a day in the COVID-19 } \\
\text { pandemic }\end{array}$ & 309 & $0.004 * *$ & $0.140 * *$ & $0.022 * *$ & 426 & $\mathbf{0 . 0 1 2} * *$ & $0.055 * *$ & $0.109 * *$ \\
\hline Increase in expenditures in the COVID-19 pandemic & 309 & 0.006* & $p<0.001$ & $0.005 *$ & 426 & $\mathbf{0 . 0 0 5}^{*}$ & $p<0.001 *$ & $0.041 *$ \\
\hline \multicolumn{9}{|l|}{ During the COVID-19 Pandemic } \\
\hline Smoking & 193 & $0.018 * *$ & $0.427 * *$ & $0.121 * *$ & 198 & $p<0.001 *$ & $p<0.001 *$ & $p<0.001 *$ \\
\hline Physical activity & 298 & $p<0.001 * *$ & $\mathbf{0 . 0 3 5} * *$ & $0.011 * *$ & 418 & $0.016 * *$ & $0.027 * *$ & $p<0.001 * *$ \\
\hline Daily sleep duration & 303 & $p<0.001 * *$ & $p<0.001 * *$ & $p<0.001^{* * *}$ & 422 & $p<0.001 * *$ & $p<0.001 * *$ & $p<0.001$ **: \\
\hline Social media use & 294 & $0.269 * *$ & $0.007 * *$ & $0.007 * *$ & 417 & $p<0.001 * *$ & $p<0.001 * *$ & $p<0.001 * *$ \\
\hline Alcohol consumption & 152 & 0.040 & 0.116 & 0.018 & 159 & $\mathbf{0 . 0 3 5} * *$ & $0.115 * *$ & $0.055^{* *}$ \\
\hline Number of meals per day & 304 & $p<0.001 * *$ & $p<0.001 * *$ & $p<0.001 * *$ & 420 & $p<0.001 * *$ & $p<0.001 * *$ & $p<0.001 * *$ \\
\hline Appetite condition & 305 & $p<0.001 * *$ & $p<0.001 * *$ & $p<0.001 * *$ & 418 & $p<0.001 * *$ & $p<0.001 * *$ & $p<0.001 * *$ \\
\hline
\end{tabular}

* Mann-Whitney U test

** Kruskal-Wallis test

Table 5 The effect of socio-demographic features and working characteristics on depression, anxiety, and stress

\begin{tabular}{|c|c|c|c|c|c|c|c|}
\hline \multirow[t]{2}{*}{ Variable } & \multirow[t]{2}{*}{$\mathrm{B}$} & \multirow[t]{2}{*}{ Std. error } & \multirow[t]{2}{*}{$\beta$} & \multirow[t]{2}{*}{$\mathrm{t}$} & \multirow[t]{2}{*}{$\mathrm{p}$} & \multicolumn{2}{|l|}{$95 \% \mathrm{Cl}$} \\
\hline & & & & & & Lower & Upper \\
\hline (Constant) & 9.831 & 2.547 & & 3.860 & $<0.001$ & 4.831 & 14.831 \\
\hline Between 18 and 24 age & 2.619 & 2.205 & .085 & 1.188 & .235 & -1.709 & 6.947 \\
\hline Between 25 and -34 age & 2.343 & 2.140 & .078 & 1.095 & .274 & -1.858 & 6.543 \\
\hline Between 35 and 44 age & -1.098 & 2.364 & -.027 & -.464 & .643 & -5.740 & 3.544 \\
\hline Female & 2.323 & 1.300 & .078 & 1.787 & .074 & -.229 & 4.876 \\
\hline Working in the healthcare sector & 5.041 & 1.410 & .169 & 3.576 & $<0.001$ & 2.273 & 7.809 \\
\hline Having previous experience in the current job & -1.357 & 1.083 & -.045 & -1.253 & .211 & -3.484 & .769 \\
\hline 2.000 and $\downarrow$ income & -3.138 & 2.657 & -.045 & -1.181 & .238 & -8.356 & 2.079 \\
\hline Between 2.001 and 3.500 income & .269 & 1.441 & .008 & .186 & .852 & -2.561 & 3.098 \\
\hline Between 5.001 and 7.000 income & -1.699 & 1.553 & -.044 & -1.094 & .274 & -4.748 & 1.349 \\
\hline Between 7.000 and 10.000 income & -1.638 & 1.619 & -.041 & -1.012 & .312 & -4.817 & 1.541 \\
\hline $1-8 \mathrm{~h}$ daily working time & -2.841 & 1.194 & -.096 & -2.380 & $<0.05$ & -5.185 & -.497 \\
\hline $17-24 \mathrm{~h}$ daily working time & -.965 & 1.733 & -.024 & -.557 & .578 & -4.368 & 2.438 \\
\hline Decrease daily working hours & 1.637 & 1.565 & .041 & 1.046 & .296 & -1.436 & 4.711 \\
\hline İncrease daily working hours & -.310 & 1.164 & -.010 & -.266 & .790 & -2.595 & 1.976 \\
\hline İncrease in expenditures & 3.459 & 1.081 & .115 & 3.200 & $<0.001$ & 1.337 & 5.582 \\
\hline
\end{tabular}

R: $.322 \mathrm{R}^{2}: .085$

F: $5.505 \mathrm{p}:<0.001$

a Dependent variable: Total_DASS_21_Scale

b. Reference categories: age 45 and $\uparrow$; male gender; working in the service sector; not having previous experience in the current job; income between 3.501 and 5.000 TRY; work hours in the range from 9 to $16 \mathrm{~h}$ a day; not having change daily working hours during the COVID-19 pandemic; not having an increase in expenditures during the COVID-19 pandemic 
sector employees during the pandemic; while this relationship has not been observed in service sector employees. There are different findings in the literature. In the study by Huang and Zhao (2020), it has been found out that anxiety and depression symptoms were common in young study participants from the studied population. Olaseni et al. (2020) did not find a significant difference between gender and depression during the pandemic, while a relationship was found between gender and anxiety (Olaseni et al. 2020). Mazza et al. (2020) found higher levels of depression and anxiety in women in society during the pandemic. The studies about the previous SARS outbreaks reported that gender factor increased the likelihood of high DASS scores in women (Hammen 2018) or men (Koh et al. 2005). Most of the participants in our study are nurses. It is known that nurses have different education levels such as high school degree, undergraduate degree, master's degree, and doctorate. It can be argued that high school graduate health sector employees need more support compared to their colleagues, who completed higher educational levels. Therefore, high educational levels of health sector employees resulted in obtaining correct information about COVID-19 despite the unfavourable influences of the working conditions in healthcare institutions (Mazza et al. 2020). However, the high DASS scores in service sector employees with the postgraduate levels of education suggest that anxiety levels may have increased because of the high awareness levels of those individuals.

The fourth finding of our study is the high anxiety scores in employees from both sectors reporting increases in expenditures (cleaning, food, etc.) during the COVID19 pandemic. The progress of the pandemic, staying home, mandatory quarantine, and the uncertainty of the process caused stockpiling anxiously and increased the tendency of people for shopping, as well as, increased looting (Grashuis et al. 2020). Furthermore, an increased demand occurred in health sector employees in the COVID-19 pandemic for cleaning materials to prevent virus transmission and for organic products to strengthen the immune system (Gershman 2020; Chang et al. 2020). According to the results of that study, it can be argued that health sector employees compared to other occupational groups have tended to shop hygiene products and immunity-enhancing products more to take individual precautions and avoid the risk of transmission. Another point to note is the increased anxiety levels occurring with increased expenditures regardless of the occupation of individuals. It can be suggested that individuals, who are more psychologically affected by the pandemic, tend to spend more. This may be reflected in the behavioural tendency for shopping associated with their vulnerability to the pandemic. However, it is also possible that the increase in expenses causes depression, anxiety or stress by increasing the economic burden on the individuals. Within this scope, there is a need for comprehensive studies to evaluate the spending patterns and psychological outcomes occurring during the pandemic.

The fifth finding is the high DASS scores of health sector employees, who have started smoking more during the COVID-19 pandemic. During the pandemic; starting to smoke or increasing the frequency of smoking can be observed in health sector employees, who are under stress because of the intense work (Koczkodaj et al. 2020). Many smokers report that smoking helps to cope with stress and increases the ability to concentrate (West 2017). Uncertainty and stress can cause smokers to smoke more and cause individuals, who stopped smoking, to start again (Patwardhan 2020). Indeed, it is reported that adults started to smoke more and $3.3 \%$ of smokers considered to stop smoking during the COVID-19 pandemic (Di Renzo et al. 2020). However; despite the reports in the literature showing increased severity of COVID-19 in smokers, increased smoking and its association with increased stress levels are worrisome as observed in our study and in other similar studies that investigated this association and supported our study (Vardavas and Nikitara 2020; Guan et al. 2020). In this respect, it can be argued that our study demonstrates the necessity of conducting studies on this subject matter.

The sixth finding of our study is the presence of significant differences between reduced appetite and general stress levels in both of the sectors examined in this study. Being adversely affected by the pandemic and being under emotional stress may reduce appetite and cause a reduction in the number of meals a day, but increases in appetite can sometimes be observed in some individuals conversely. Di Renzo et al. (2020) found out that more than half of the adults experienced changes in appetite and, of those individuals, $34.4 \%$ had increased appetite. Although conditions become challenging in the pandemic, it is suggested that it is still important to coordinate the diet and snack supply to hospital employees, as well as the provision of information and training about adequate and balanced nutrition, to maintain the well-being of health sector employees.

The seventh finding in our study is the increased mean scores of the stress, depression, and anxiety subscales in individuals from both sectors, who reported shortened sleep duration compared to the time before the COVID-19 pandemic. In the literature, it has been reported that there is a negative relationship between anxiety levels and the sleep quality (Xiao et al. 2020) and that there are insomnia symptoms in health sector employees (Baddahdah 2020; Tan et al. 2020). Poor and reduced sleep quality has also been found in health sector employees working under high risk ( $\mathrm{Li}$ et al. 2020). In a study conducted in China by Huang and Zhao (2020), it was determined that the sleep quality of health sector employees was lower compared to employees from other occupational groups such 
as teachers, company employees, and municipal employees. In the present study; the number of employees, who stated that they were sleep-deprived compared to previous times before the pandemic was found to be higher compared to the number of employees from other sectors. Sleep deprivation in service sector employees can increase the general stress level or cause work-related disruptions; however, insufficient sleep in health sector employees can lead to not only untoward psychological effects but serious and irreversible errors in medical care, the administration of medications, and the conduct of treatment plans, threatening the life of patients. Indeed, a relationship between sleep quality and anxiety levels has been found in health sector employees, who provide care for COVID19 patients (Xiao et al. 2020). From this point of view, it can be suggested that there is a need for implementing mechanisms to strengthen the general health-related behaviours of health sector employees during crises such as the current COVID-19 pandemic.

The eighth finding is the high levels of overall stress in employees from both sectors reporting reductions in physical activity levels; however, the stress levels were higher among health sector employees. It is known that physical activity contributes significantly to preventing stress, promoting the well-being, and improving mental health such as inducing happiness. However, intensive working conditions and isolation measures may have interrupted the engagement in healthy lifestyle behaviours such as physical activity, exercise, and sports.

The ninth finding is the reduction in the use of social media among health sector employees resulting in increases in the symptoms of depression, anxiety, and stress. Health sector employees may not have sufficient time to use social media because of busy working conditions, increased work, and fatigue. It is known that information pollution in social media leads to stress, depression, anxiety, and nervousness (Ni et al. 2020; Gao et al. 2020). However, social media is beneficial conversely as it allows for access to information. The results in the present study suggest that social media resources are managed well by the Ministry of Health and the respective authorities in Turkey. Furthermore, the study findings confirm that social media provides effective means in raising public awareness by disseminating important health-related information resulting in favourable changes in the existing knowledge, attitudes, and practices. However, no relationships between social media use and emotional outcomes have been found among service sector employees. Occupational status and demographic differences are thought to be the factors influencing social media use. The use of social media may vary among individuals depending on demographic and cultural characteristics including emotional and psychosocial development levels and differences in the levels of awareness.

\section{Limitations and strengths of the study}

The limitations of this study include the use of a longitudinal approach in the study conduct, the lack of evaluation of improvements in mental health, and the use of online questionnaires and self-report tools for the psychological evaluation. Because the users of the Google Forms application are mostly young people, the age distribution of the study participants is not expected to represent all age groups in the population. It may be necessary to include participants equally from both genders and all age groups. The strengths of the study include the evaluation of the mental state of health sector employees and the participation of an adequate number of service sector employees despite the wide range of distribution.

\section{Conclusion}

This study highlights that depression, anxiety and stress levels of health sector employees have increased more compared to the levels in individuals working in the service sector, resulting in unfavourable consequences in their lifestyle behaviours. Health sector employees were also emotionally affected by increased working hours and shift changes during the pandemic. Our study provides significant findings regarding the mental health of individuals who continued working during the pandemic. To implement effective mental health interventions to risk groups and affected people in the COVID-19 pandemic, the recommendations of leading organizations, including WHO and ILO, should be implemented effectively concerning occupational health. Clinical interviews should be performed in future studies for the evaluation of employee mental health.

Acknowledgements This study was funded by the Y1ldırım Beyazit University Scientific Research Projects Coordination Unit within the scope of this study (ID:2109). The authors would like to acknowledge the participant for their contribution to the study.

Authors' contributions EK designed the article. EK and AA conducted the research data collecting. FÖ analysed the data. EK drafted the manuscript with contributions and reviews from FÖ, AA and HÖ. All contributors have given final approval of the version to be published.

Funding This study was funded by Ankara Yıldırım Beyazıt University as a Scientific Research Project (ID:2109).

Availability of data and materials The data of the study are only accessible by the researchers.

Code availability Not applicable. 


\section{Compliance with ethical standards}

Conflicts of interest The authors report no actual or potential conflict of interest.

\section{References}

Badahdah A, Khamis F, Al Mahyijari N, Al Balushi M, Al Hatmi H, Al Salmi I, Albulushi Z, Al Noomani J (2020) The mental health of health care workers in Oman during the COVID-19 pandemic. Int J Soc Psychiatry. https://doi.org/10.1177/00207 64020939596

Brooks SK, Webster RK, Smith LE, Woodland L, Wessely S, Greenberg N, Rubin GJ (2020) The psychological impact of quarantine and how to reduce it: rapid review of the evidence. Lancet 395:912-920. https://doi.org/10.1016/S0140-6736(20)30460-8

Chang A, Schnall AH, Law R, Bronstein AC, Marraffa JM, Spiller HA, Hays HL, Funk AR, Mercurio-Zappala M, Calello DP, Aleguas A (2020) Cleaning and disinfectant chemical exposures and temporal associations with COVID-19-National Poison Data System, United States, January 1, 2020-March 31, 2020. MMWR Morb Mortal Wkly Rep Title 69(16):496-498. https://doi.org/https:// doi.org/10.15585/mmwr.mm6916e1

Chew NW, Lee GK, Tan BY, Jing M, Goh Y, Ngiam NJ, Yeo LL, Ahmad A, Khan FA, Shanmugam GN, Sharma AK (2020) A multinational, multicentre study on the psychological outcomes and associated physical symptoms amongst healthcare workers during COVID-19 outbreak. Brain Behav Immun 88:559-565. https:// doi.org/10.1016/j.bbi.2020.04.049

Di Renzo L, Gualtieri P, Pivari F, Soldati L, Attinà A, Cinelli G, Leggeri C, Caparello G, Barrea L, Scerbo F, Esposito E (2020) Eating habits and lifestyle changes during COVID-19 lockdown: an Italian survey. J Transl Med 18(1):1-15. https://doi.org/10.1186/ s12967-020-02399-5

Gao J, Zheng P, Jia Y, Chen H, Mao Y, Chen S, Wang Y, Fu H, Dai J (2020) Mental health problems and social media exposure during COVID-19 outbreak. PLoS ONE 15(4):e0231924. https://doi. org/10.1371/journal.pone.023194

Gershman, J (2020) CDC survey shows adults are using unsafe practices with household cleaning and disinfectant products to prevent COVID-19. https://www.pharmacytimes.com/news/cdc-surve y-shows-adults-are-using-unsafe-practices-with-household-clean ing-and-disinfectant-products-to-prevent-covid-19. Accessed 5 Aug 2020

Grashuis J, Skevas T, Segovia MS (2020) Grocery Shopping Preferences during the COVID-19 pandemic. Sustainability 12(13):5369. https://doi.org/10.3390/su12135369

Guan WJ, Ni ZY, Hu Y, Liang WH, Ou CQ, He JX, Du B (2020) Clinical characteristics of coronavirus disease 2019 in China. $\mathrm{N}$ Engl J Med 382(18):1708-1720. https://doi.org/10.1056/NEJMo a2002032

Hammen C (2018) Risk factors for depression: an autobiographical review. Annu Rev Clin Psychol 14:1-28. https://doi.org/10.1146/ annurev-clinpsy-050817-084811

Huang Y, Zhao N (2020) Chinese mental health burden during the COVID-19 pandemic. Asian J Psychiatry 51:102052. https://doi. org/10.1016/j.ajp.2020.102052

Ji D, Ji YJ, Duan XZ, Li WG, Sun ZQ, Song XA, Chen GF (2017) Prevalence of psychological symptoms among Ebola survivors and healthcare workers during the 2014-2015 Ebola outbreak in Sierra Leone: a cross-sectional study. Oncotarget 8(8):12784. https://doi.org/10.18632/oncotarget.14498
Koczkodaj P, Cedzyńska M, Didkowska J (2020) Smoking and SARSCoV-2: are polish health professionals at higher risk of infection? Tobacco Induced Dis. https://doi.org/10.18332/tid/122760

Koh D, Lim MK, Chia SE, Ko SM, Quian F, Ng V, Fones C (2005) Risk perception and impact of Severe Acute Respiratory Syndrome (SARS) on work and personal lives of healthcare workers in Singapore: what can we learn? Med Care 43:676-682. https:// doi.org/10.1097/01.mlr.0000167181.36730.cc

Lai J, Ma S, Wang Y, Cai Z, Hu J, Wei N, Tan H (2020) Factors associated with mental health outcomes among health care workers exposed to coronavirus disease 2019. JAMA Network Open 3(3):1-12. https://doi.org/10.1001/jamanetworkopen.2020.3976

Li J, Kong X, Li F, Wu B, Xu H, Wu T, Chu J, Liu J (2020) Sleep quality and health in healthcare professionals fighting against COVID19: a comparative study between high risk area (Hubei Province) and low risk area (Jiangsu Province) in China. DOI: https://doi. org/10.21203/rs.3.rs-27217/v1

Lin CY, Peng YC, Wu YH, Chang J, Chan CH, Yang DY (2007) The psychological effect of severe acute respiratory syndrome on emergency department staff. Emerg Med J 24(1):12-17. https:// doi.org/10.1136/emj.2006.035089

Mazza C, Ricci E, Biondi S, Colasanti M, Ferracuti S, Napoli C, Roma P (2020) A nationwide survey of psychological distress among Italian people during the COVID-19 pandemic: Immediate psychological responses and associated factors. Int J Environ Res Public Health 17(9):3165. https://doi.org/10.3390/ijerph17093165

Ni MY, Yang L, Leung CM, Li N, Yao XI, Wang Y, L ... Liao Q, (2020) Mental health, risk factors, and social media use during the COVID-19 epidemic and cordon sanitaire among the community and health professionals in Wuhan, China: Cross-sectional survey. JMIR mental health 7(5):e19009. https://doi.org/10.2196/19009

Nguyen T, Duong Bang D, Wolff A (2020) 2019 Novel Coronavirus Disease (COVID-19): paving the road for rapid detection and point-of-care diagnostics. Micromachines 11(3):306. https://doi. org/10.3390/mi11030306

Olaseni AO, Akinsola OS, Agberotimi SF, Oguntayo R (2020) Psychological distress experiences of Nigerians amid COVID-19 Pandemic. https://doi.org/https://doi.org/10.1016/j.ssaho.2020.10005 2

Özdin S, Bayrak Özdin Ş (2020) Levels and predictors of anxiety, depression and health anxiety during COVID-19 pandemic in Turkish society: the importance of gender. Int J Soc Psychiatry 5:504-511. https://doi.org/10.1177/0020764020927051

Patwardhan P (2020) COVID-19: Risk of increase in smoking rates among England's 6 million smokers and relapse among England's 11 million ex-smokers. BJGP Open. https://doi.org/10.3399/bjgpo pen20X101067

Ruiz-Fernández MD, Ramos-Pichardo JD, Ibáñez-Masero O, CabreraTroya J, Carmona-Rega MI, Ortega-Galán ÁM (2020) Compassion fatigue, burnout, compassion satisfaction and perceived stress in healthcare professionals during the COVID-19 health crisis in Spain. J Clin Nurs 29:4321-4330. https://doi.org/10.1111/ jocn. 15469

Sasangohar F, Jones SL, Masud FN, Vahidy FS, Kash BA (2020) Provider burnout and fatigue during the COVID-19 pandemic: lessons learned from a high-volume intensive care unit. Anesth Analg 131(1):106-111. https://doi.org/10.1213/ANE.0000000000 004866

Tan W, Hao F, McIntyre RS, Jiang L, Jiang X, Zhang L, Zhao X, Zou Y, Hu Y, Luo X, Zhang Z (2020) Is returning to work during the COVID-19 pandemic stressful? A study on immediate mental health status and psychoneuroimmunity prevention measures of Chinese workforce. Brain Behavior Immunity. https://doi.org/https ://doi.org/10.1016/j.bbi.2020.04.055

Temsah MH, Al-Sohime F, Alamro N, Al-Eyadhy A, Al-Hasan K, Jamal A, Al-Subaie S (2020) The psychological impact of 
COVID-19 pandemic on health care workers in a MERS-CoV endemic country. J Infect Public Health 13:877-882. https://doi. org/10.1016/j.jiph.2020.05.021

Teng Z, Wei Z, Qiu Y, Tan Y, Chen J, Tang H, Huang J (2020) Psychological status and fatigue of frontline staff two months after the COVID-19 pandemic outbreak in China: A cross-sectional study. J Affect Disord 275:247-252. https://doi.org/10.1016/j. jad.2020.06.032

Turkey Cargo, Courier and Logistics Operators Association (KARID). (2020). Our Press Bulletin. http://www.karid.org.tr/basin-bulte nimiz-koronavirus-tehlikesine-karsi-onlemlerimizi-aliyoruz/ Accessed 26 Apr 2020

T.R. Ministry of Health (2020) Press release dated April 29, 2020 https ://www.istabip.org.tr/koronavirus/Haberler/5795/covid-19-ileenfekte-saglik-calisanlarinin-bildiriminde-karsilasilan-sorun lara-yonelik-rehber Accessed 30 Aug 2020

Vardavas CI, Nikitara K (2020) COVID-19 and smoking: A systematic review of the evidence. Tobacco Induced Dis 18:20. https://doi. org/https://doi.org/10.18332/tid/119324

Wang C, Pan R, Wan X, Tan Y, Xu L, Ho CS, Ho RC (2020) Immediate psychological responses and associated factors during the initial stage of the 2019 coronavirus disease (COVID-19) epidemic among the general population in China. Int J Environ Res Public Health 17(5):1729. http://https://doi.org/10.3390/ijerph17051729

West R (2017) Tobacco smoking: health impact, prevalence, correlates and interventions. Psychol Health 32(8):1018-1036. https://doi. org/10.1080/08870446.2017.1325890

World Health Organization (WHO) (2020a) WHO Statement regarding cluster of pneumonia cases in Wuhan, China. https://www.who. int/china/news/detail/09-01-2020-who-statement-regarding-clust er-of-pneumonia-cases-in-wuhan-china Accessed 4 May 2020

World Health Organization (WHO) (2020b) WHO calls for healthy, safe and decent working conditions for all health workers, amidst
COVID-19 pandemic. https://www.who.int/news-room/detail/28 04-2020-who-calls-for-healthy-safe-and-decent-working-condi tions-for-all-health-workers-amidst-covid-19-pandemic. Accessed 6 Aug 2020

Wu P, Fang Y, Guan Z, Fan B, Kong J, Yao Z, Liu X, Fuller CJ, Susser E, Lu J, Hoven CW (2009) The psychological impact of the SARS epidemic on hospital employees in China: exposure, risk perception, and altruistic acceptance of risk. Canadian journal of psychiatry. Revue canadienne de psychiatrie 54(5): 302-311. https:// doi.org/https://doi.org/10.1177/070674370905400504

Xiao H, Zhang Y, Kong D, Li S, Yang N (2020) The effects of social support on sleep quality of medical staff treating patients with coronavirus disease 2019 (COVID-19) in January and February 2020 in China. Med Sci Monitor 26:e923549. https://doi.org/https ://doi.org/10.12659/MSM.923549

Yilmaz Ö, Boz H, Arslan A (2017) Reliability and validity study of the Turkish short form of the Depression Anxiety Stress Scale (DASS-21). J Finance Econ Soc Res 2(2):78-91

Zhan M, Qin Y, Xue X, Zhu S (2020) Death from COVID-19 of 23 health care workers in China. N Engl J Med 382:2267-2268. https ://doi.org/10.1056/NEJMc2005696

Zhu Z, Xu S, Wang H, Liu Z, Wu J, Li G, Miao J, Zhang C, Yang Y, Sun W, Zhu S (2020) COVID-19 in Wuhan: immediate psychological impact on 5062 Health Workers. MedRxiv. https://doi. org/10.1101/2020.02.20.20025338

Publisher's Note Springer Nature remains neutral with regard to jurisdictional claims in published maps and institutional affiliations. 